\title{
Research on the Empirical Analysis of Financial Input for Scientific \& Technology and Economic Growth:In the Shanxi province
}

\author{
Xing $\mathrm{Li}$ \\ Asia University No. 500, Lioufeng Rd., Wufeng, \\ Taichung City 41354,Taiwan \\ e-mail: leebj@189.cn
}

\author{
Shieh-Liang Chen \\ Asia University No. 500, Lioufeng Rd., Wufeng, \\ Taichung City 41354, Taiwan \\ e-mail:peterchen@asia.edu.tw
}

\author{
Mian Lin \\ Asia University No. 500, Lioufeng Rd., Wufeng, \\ Taichung City 41354,Taiwan \\ e-mail: nikkinino@aliyun.com
}

\begin{abstract}
The papper use quantitative analysis method of the dynamic economy to make the empirical analysis on the relationship between Scientific \& Technology input and economic growth of Shanxi province frame 1995 to 2010 based on VAR model. Results the research have showed that there is a long-term stable equilibrium relationship between Scientific \& Technology input and economic growth; Scientific \& Technology input has an intense promotion on the economic growth. Meanwhile, the economic growth also boost the Scientific \& Technology input.
\end{abstract}

Keywords:Investment;EconomicGrowth;VAR Model;Granger Causality Test.

\section{INTRODUCTION}

Scientific \& Technology input and economic growth are two interactional aspects of one system. On the one hand,the increase in Scientific \& Technology input can promote technical progress, which drives the economic growth and also have become the most imortant factor to decide the speed and quality of the economic growth. The resulting ability of innovation in the Scientific \& Technology is the crucial factor of competition between contries and regions.On the other hand, the rapid development of economy provides a good material basis to Scientific \& Technology input and also a maket demands to technical progress, which make innovation possible. The interaction and mutual development in economic growth and technological progress has promoted the progress of whole society. At present, increase investment in Scientific \& Technology has been treated as the main means of promoting the economic progress and enhancing comprehensive competitiveness in many contries and regions..According to the guiding ideology of the 12th Five-Year Plan of Scientific \& Technology Development, Shanxi province declared that the economic development of Shanxi should be given a priority development and pre-deployment, and propotion that the investment in scientific research and technological development takes in the regional GDP should be over $1.5 \%$. And in the new situation that the capability of independent innovation has been vigorously promoted, correctly understanding the dynamic equilibrium between financial input in Scientific \& Technology and economic growth of Shanxi Province will provide an important refrence value both to the establishment of strategies in Scientific \& Technology development and the improvement of output level in Scientific \& Technology input.

\section{EMPIRICAL STUDY OF THE DYNAMIC RELATIONSHIP BETWEEN SCIENTIFIC \& TECHNOLOGY INPUT AND ECONOMIC GROWTH}

In order to explore the relation between scientific-andtechnological input and economic growth, the VAR model was used in this paper to analyse the dynamic relationship of the figures between Scientific \& Technology input and economic growth in Shanxi province with the hope that it can offer a refrence both in theory and practice for the government and other departments to make policies in Scientific \& Technology management.

\section{A. Selection of Data And Variables}

\section{1) Input Index of Scientific \& Technology}

Proportion that the R\&D expenditure takes in the GDP is the most important and comprehensive index to weigh the level of Scientific \& Technology input in a country or a region.In research of the effects that Scientific \& Technology input has brought to the economic growth in Shanxi,the internal expenditure of R\&D is chosen in the paper as the indicator of the Scientific \& Technology input,which is more correspond to the practical situation of the study input in science and technology in Shanxi Province.

\section{2) Indicater of Economic Growth}


Index of the GDP of Shanxi Province is selected in the paper as the variable of the economic growth; according to the availability of data and the selection of indicator, the STI and the GDP from 1995to2010in Shanxi Province are adopted in this article. GDP index $(1995=100)$ and the index of price $(1995=100)$ are used to adjust the data respectively to eliminate the price factor. To take the natural logarithm of GDP and STI, $\ln (\mathrm{GDP})$ and $\ln (\mathrm{STI})$, which has three benefits:the original cointegration relationship will not be changed;the trend of linearization is assured;the heteroskedasticity in the economic time series can be eliminated.The data progressing in this article was finished with the software eviews6.0.

\section{B. Empirical Analysis}

\section{1) ADF Integration Test of Time Series}

In empirical analysis, the stability of economic time should be conducted stationary tests firstly to avoid spurious regression occurs after a simple one, because time series of economic variables have a non-stability and by doing so, the equilibrium relationship between variables can be kept as well;the general way of stationary test is the test of unit root, but in this paper the $\mathrm{ADF}$ test method is used to test the unit root of the variables. The result of the test shows that the level sequences of two variables are non-stationary, but their first order diffrence sequences are steady at significance level of $5 \%$ or $10 \%$, i.e.they are LNGDP-I(1) and LNSTII(1). LNSTI and LNGDP is a single whole sequence,so the cointegration analysis can be used to analyse the time series data.

2) Cointegration Test Btween Columns

Although the LNGDP and LNSTI are unsteady sequences, there may be some linear combinations that can reflect the cointegration relationship between variables. Johansen(1995) Maximum Likehood Estimation is employed to take a cointegration test on time series.Besides, the strcture model of VAR must be confirmed first before testing,since cointegration test is based on VAR model.Results of the test has showed that the best model is the VAR mdel whose lag order is 2 . The lag order number that cointegration test has chosen should equal to the optimal lag order number of the unconstrained VAR model minus 1, namely,the lag order number of cointegration test of VAR model is 1 . After the cointegration relationship between LNGDP and LNSTI is tested by Johansen Trace Test and the largest eigenvalue contegration test,it prove that there is a cointegration equation between LNGDP and LNSTI at the significance level of $1 \%$, which indicates that there is a common trend between these variables. In other words, it shows that there is a long-term stable equilibrium relationship between economic growth and scientific-andtechnological input. The estimated cointegration relation is :LNGDP=5.147+0.7648LNSTI In the pattern, the coefficient of regression 0.7648 is the elasticity coefficient of economic growth on the R\&D investment, i.e. each additional $1 \%$ in $\mathrm{R} \& \mathrm{D}$ investment will bring about an averagely additional $0.76 \%$ in total production of Shanxi Province, which shows that Scientific \& Technology input has the pushing effect on GDP.

\section{3) Estimation of VAR model}

As is analysed above,the optimal model of VAR is the model whose lag order number is 2 . So the sample data of LNGDP and LNSTI can be used to build the VAR(2) model, and the impulse response function can be used to explain it. The vector auto-regression model as showed in table 1.

\begin{tabular}{|c|c|c|}
\hline & LNGDP & LNSTI \\
\hline LNGDP(-1) & 1.169549 & 7.946958 \\
\hline & {$[4.39938]$} & {$[2.491103]$} \\
\hline LNGDP(-2) & -0.151326 & -6.878826 \\
\hline & {$[-3.59058]$} & {$[-2.24511]$} \\
\hline LNSTI(-1) & 0.021733 & 0.438415 \\
\hline & {$[1.91801]$} & {$[1.53737]$} \\
\hline LNSTI(-2) & -0.26616 & -0.239411 \\
\hline & {$[-1.30502]$} & {$[-0.97463]$} \\
\hline C & -0.042409 & -6.126854 \\
\hline & {$[-0.26615]$} & {$[-3.19265]$} \\
\hline $\mathbf{2}$ & 0.999785 & 0.984864 \\
\hline $\bar{R}$ & 0.999691 & 0.97812 \\
\hline AIC & \multicolumn{2}{|c|}{-8.377987} \\
\hline SC & \multicolumn{2}{|c|}{-71521} \\
\hline
\end{tabular}

\section{Table 1}

\section{NOTE: Data in $[$ in table1 is t statistics}

Results of the VAR(2) model have showed that the AIC value and AC value are -8.3779 and -7.9215 , they are quite small, but their coefficients of determination are 0.9997 and 0.9781 ,which indicates that fitting degrees of the two regression functions are quite high and their overall explanatory power of the model is fine.At the lag of order 2 case, residual errors of VAR(2) are proved to obey normal distribution, no correlation and there is heteroscedasticity,meanwhile, all the reciprocal of the characteristic roots are less 1 , with JB test of normality , LM autocorrelation test and white test for heteroscedasticity, which proves the structure of $\operatorname{VAR}(2)$ is stable. Therefore,the statistical properties of $\operatorname{VAR}(2)$ is good, which can be used as the basis of pulse analysis.

\section{4) Analysis of impulse response function}

Impulse function can be employed to identify that how the variable of GDP or the disturbance of scientific-andtechnological input influence other variables through models, because VAR model has a dynamic structure. As shown in the figure $1 \& 2$,after giving the standard deviation impact of Cholesky to LNGDP and LNSTI,there must be an impulse graph accordingly. The horizontal axis stands for the follow-up period of the response function which is assumed 10 years in this figure; the vertical axis stands for the degree of response of the dependent variables to produce the explanatory variables. And the lines show the calculated value of the response function; dotted lines show the confidence interval of the response function value adds/minus the twice standard deviation. 


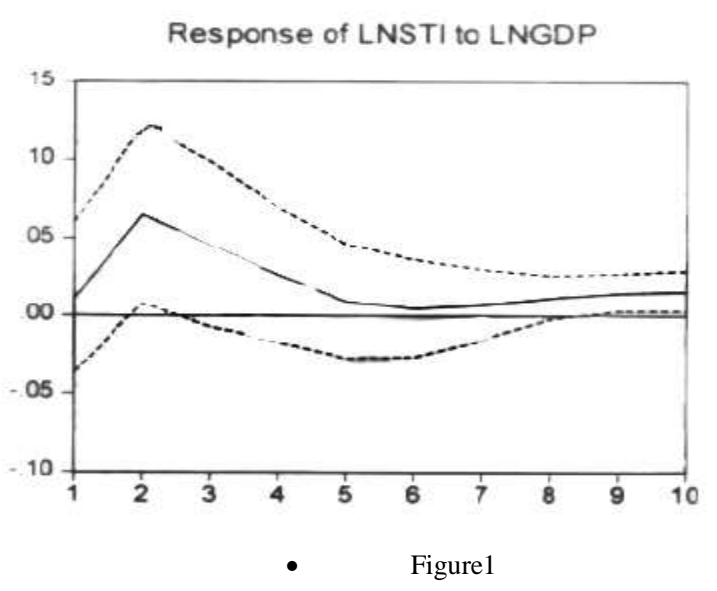

Figure1 reflects the impulse response in which economic growth changed by the impact of investment in science and technology. From figure1, it can be seen that after a standard devision of the impact being put on the Scientific \& Technology input at the current period,a rapid positive response will be caused to the economic growth,which decreses after it reaches the top point at the 2nd term, and then shows a stable sign of positive response after the 5th term. It's conclusion further supports the empirical result of the cointegration and explains the close relationship between Scientific \& Technology and GDP growth.Therefore, the government should adopt a long-term policy rather than a short-term one on the drafting of Scientific \& Technology input strategies, thus can stimulate the transform of Scientific \& Technology input to productivity effectively and finally to the practical output of economy.

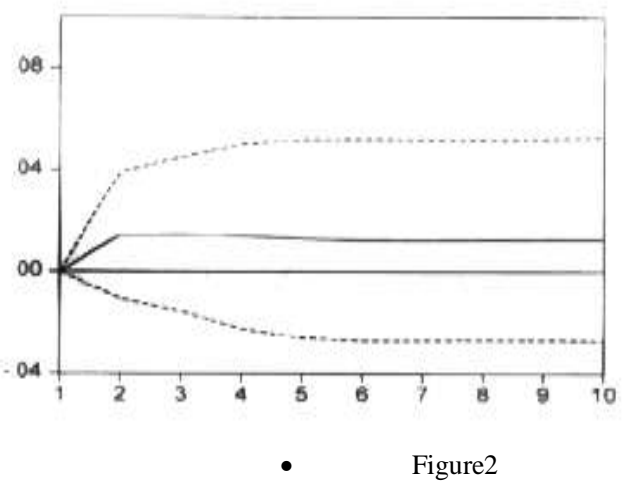

Figure2 shows that GDP always has a positive response to
Scientific \& Technology input and one of it's diturbances of standard devision reaches at the highest point at the 2 nd term, then become stable. Consiquently, there is a close relationship between scientific-and-technological input and GDP, i.e. economic growth can promote the rise in Scientific $\&$ Technology input, with a long-term changing trend.

5) Granger cauality test based on VECM.

Results of the cointegration has proved that there is a long-term stable equilibrium relationship between the economic growth and investment in science and technology in Shanxi,but whether it is a causal relationship or not still remains further study.In 1987,Engel and Gmnge proved that after introducing the cointegration test, the process of first order difference can be described by the VAR process of finite order.Namely, vector error correction model can be established as below.

$\left(\begin{array}{l}\Delta L N G D P_{1} \\ \Delta L N S T I_{1}\end{array}\right)=\left(\begin{array}{l}1.3196 \\ -4.530\end{array}\right)=\left(\begin{array}{ll}0.0289 & 0.0217 \\ 3.7721 & 0.4587\end{array}\right)$
$\left(\begin{array}{l}\Delta L N G D P_{1-1} \\ \Delta L N S T I_{1-1}\end{array}\right)+\left(\begin{array}{ll}0.1392 & 0.0335 \\ 9.5290 & 0.2041\end{array}\right)\left(\begin{array}{l}\Delta L N G D P_{1-2} \\ \Delta L N S T I_{1-2}\end{array}\right)+\ldots . .+\left(\begin{array}{l}-0.0161 \\ -1.8704\end{array}\right) E C M_{1-1}$

From the model,it can be seen that their coefficientts are -0.0161and-1.8704, which meets the reversion mechanism, but Scientific \& Technology input has a narrow adjustment range of GDP deviates from the long-term equilibrium. By using Wald test to do a joint inspection on the significance of coefficients of the equation error correction model, the long-term and short-term causual relationship direction of the variables can be confirmed. The results of the test as shown in form2. Whether Scientific \& Technology input is the Grander cause of economic growth or not is based on the test of LNGDP equation.From short-term, after testing $\mathrm{H} 0$ : $\Phi 11,1=\Phi 12,1=\Phi 11$, $2=\Phi 12, \quad 2=0$, the probability of $\mathrm{F}$ statistics is $\mathrm{p}=0.1457$ and at the significant level of $5 \%$,refusing to invest in science and techmology is the Granger causes of GDP growth, namely, the increase in Scientific \& Technology input is not the Granger cause of GDP growth in short-term. Further testing on whether scientific-and-technological input is the long-term cansual relationship of economic growth

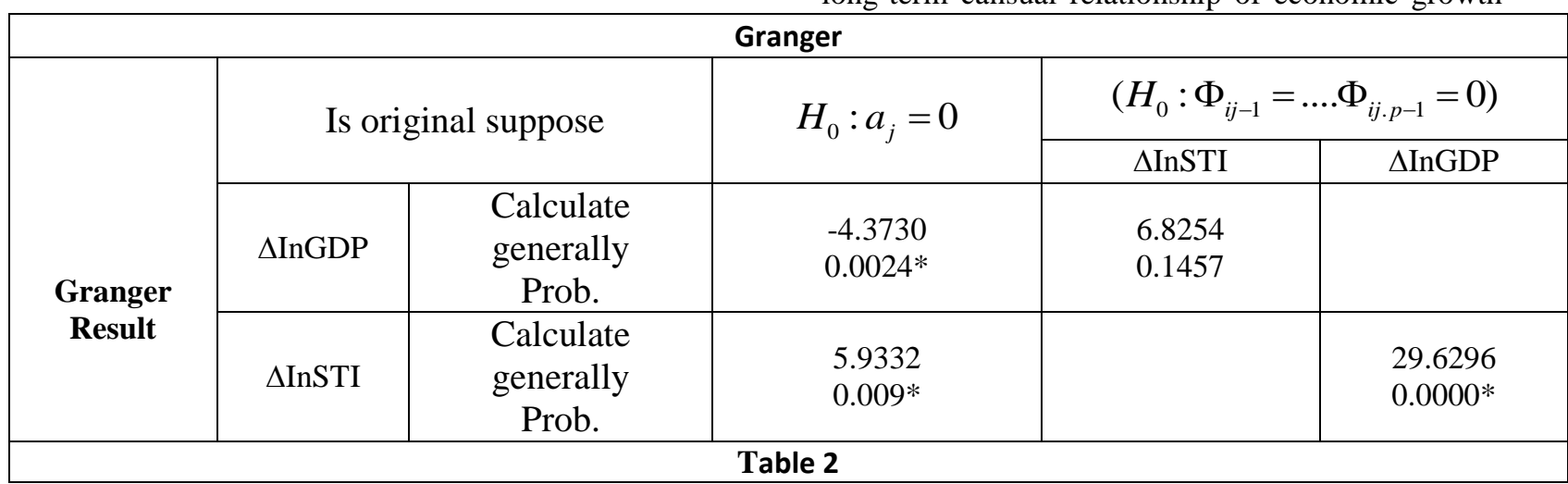


is to test HO:aj=0, and the with probability of $\mathrm{t}$ statistcs is $p=0.0024$. The test results show that the growth of scientific-and-technological input has a long-term promtion on economic growth at the significance level of $1 \%$. Whether Scientific \& Technology input is the Grander cause of economic growth or not is based on the test of LNSTI equation.From the short-term,to test H0 : $\Phi 21$, $1=\Phi 22, \quad 1=\Phi 21,2=\Phi 22,2=0$, and the with probability of $\mathrm{F}$ statistics is $\mathrm{p}=0.0000$ shows that above the significant level of $1 \%$, economic growth is the Granger cause of Scientific \& Technology input.Further testing on whether economic growth is the long-term cansual relationship of scientific-andtechnological input is to test whether it is accept that HO:aj=0, and the with probability of $t$ statistes is $\mathrm{p}=0.0009$, which reject null hypothesis,i.e.below the significent level of $1 \%$,economic growth promoted the increase of Scientific \& Technology input.

\section{CONCLUSION AND SUGgESTIONS}

The sample data of GDP and R\&D of Shanxi province from 1995 to 2010 were adopted in this papper to do an impirical study on the relationship between Scientific \& Technology input and economic growth in Shanxi, and conclusions of the study are as follows:

A, although Scientific \& Technology input and economic growth are non-stationary series, there is a long-term stable equilibrium relationship whose main character is the long-term elasticity of Scientific \& Technology inputtpo is $0.76 \%$ between them, which shows that Scientific \& Technology input brought a promotion to GDP growth of shanxi province from 1995 to 2010 .

$\mathrm{B}$, analysed from the impuse function, it is can be seen that all the positive responses between GDP and scientific-and-technological input should trend to long-term stability, which indicates there is a closely long-term relationship between them. Therefore, a long-term rather than a short-term policy should be taken to ensure that Scientific \& Technology input has long-term positively driving effects on economic growth.

$\mathrm{C}$, according to the causual relationship of VELM,there is a long-term mutual between sientific-and-technological input and GDP. In shortterm, increase in Scientific \& Technology input cannot promote ecnomic growth,while in long-term it can. It may because the effects of scientific-andtechnological input cannot be seen in short-term. Besides, it's promotion on GDP needs an intermediate transformation process, so it not likely to produce the desired significant effects with the hope of improving economic growth in short-term by adding total investment in science and technoloy.

At present, the ratio that the total input of $R \& D$ to GDP of Shanxi province is not high, and the mode of economic growth is still belongs to extension and extensive form. So it will be an inevitable choice for the strategy of invigorating the country through science, technology and education to increase support for scientific research. First, financial investment in science and technology should be more,and the stable increase mechanism of the financial investment in science and technology should be committed to improve and practable; the proportion of scintific-andtechnological input takes in financial output should be improved to keep it's proportion in GDP increased gradually. Second,utilizing efficiency of outlay for science and tehnology should be improved to transform the EXTENSIVE economic growth which used to emphasize the speed of development only into the INTENSIVE economic growth which pay more attention to the benefit and quality of developmet. Third, Scientific \& Technology exchange and transformation of it's achievements should be strenghened; the avanced techniques and scientific managerial experience in foreign countries should be taken to store more knowledge of technological advancements and economic development; In order to make scientificand-technological achievements create profits as soon as possiple, the transformation process of Scientific \& Technology achievements should be speeded up, and the achievements should be applied to the process of social production; the Scientific \& Technology content of enterprise products should be improved so that it can enhance the additional value of products.

\section{REFERENCES:}

[1] Granger, C. W. J. Investigating causal relations by econometric models and crossspectral methods. Econometrica. 1969, (37): 424-438.

[2] B. Baltagi,Econometric Analysis of Panel Data,John Wiley \& Sons, West Sussex (2008)

[3] Anil Seth. Granger causality. Scholarpedia. 2007, 2 (7): 1667. doi:10.4249/scholarpedia.1667.

[4] Hacker R.S. and Hatemi-J A. (2006) "Tests for causality between integrated variables using asymptotic and bootstrap distributions: theory and application", Applied Economics, Vol. 38(13), pp. 1489-1500.

[5] Mandelbrot, Benoit. The variation of certain speculative prices. Journal of Business. 1963, 36 (1): 394-419. doi:10.1086/294632.

[6] Hatemi-J, A. Asymmetric causality tests with an application. Empirical Economics. 2012, 42 (6): forthcoming. doi:10.1007/s00181-011-0484-x.

[7] Shieh-Liang Chen, Hao-An Liang, Cause mapping of simple and complex marketing strategies, Journal of Business Research, 67 (2014) pp-2867-2876

[8] Freeman, A.(1993).A Survey of International Banking.The Economist, 10,1-37.

[9] Hsieh, D.(1993).Implication of Nonlinear Dynamics for Financial Risk Management.Journal of Financial and Quantitative Analysis,28(1),41-46.

[10] Kaminsky, G.,Lizondo, S.,Carmen, M.(1998).Leading Indicators of Currency Crisis.International Monetary Fund,145,1-148.

[11] Smithaon, C.,Minton, L.(1996). Value at Risk.Risk,9,25-27. 
[12] Liao.C,Shu-Hui Chuang,To, P.How knowledge management mediates the relationship between environment and organizational structure. JOURNAL OF BUSINESS RESEARCH,2011.Apr,64(7):pp:728736.

[13] S. Nickel,Biases in dynamic models with fixed effects,Econometrica,49 (6) (1981), pp. 1417-1426

[14] Lixing, 'How to improve the Quality and Efficiency of Economic Audit on University leaders leaving',Journal of Longdong University,1,(2013),pp.99-101

[15] D.-H. Ahn,J. Boudoukh, M.Richardson, R.F.Whitelaw,Optimal risk management using options, Journal of Finance, 54 (1999), pp. 359-375

[16] W.W. Hogan, J.M. Warren,Computation of the efficient boundary in the E-S portfolio selection model,Journal of Financial and Quantitative Analysis, 7 (1972), pp. 1881-1896

[17] Giannini, C, Topics in structural VAR econometrics. Lecture Notes in Economics and Mathematical Systems No. 381, Springer-Verlag, Berlin,1992. 